\title{
Direito do trabalho das mulheres e a reforma trabalhista
}

\author{
Women's labor law and labor reform \\ Iris Soier do Nascimento de Andrade1 \\ Sarah Luana Alves Barbosa2
}

\begin{abstract}
RESUMO
A Lei n. 13.467/2017, por meio da qual foi realizada a denominada reforma trabalhista, procedeu com diversas alterações no texto celetista, o objetivo do presente trabalho é estudar o trabalho da mulher e as alterações realizadas pela Reforma Trabalhista, analisando se houve mitigação de direitos e tentativa de precarização das condições de trabalho.

PALAVRAS-CHAVE: Direito do Trabalho. Reforma Trabalhista. Direito
\end{abstract} das Mulheres.

\begin{abstract}
The Law $n^{\circ} .13 .467$ / 2017, through which the so-called labor reform was carried out, proceeded with several changes in the consolidation of labor laws text. Thus, the objective of this paper is to study the work of women and the changes made by the Labor Reform, analyzing whether there was any mitigation of rights and an attempt to precarious working conditions. KEYWORDS: Labor Law. Labor Reform. Women's Rights.
\end{abstract}

$$
* * *
$$

\section{Introdução}

Em novembro de 2019, a Lei 13.467 de 13 de julho de 2017, que alterou a Consolidação das Leis do Trabalho (CLT), assim como as Leis nos 6.019/74,

1 Pós-graduanda em Direito Material e Processual do Trabalho na Faculdade de Direito Milton Campos. Pós-graduada em Advocacia Cível pela Escola Superior de Advocacia (ESA - OAB/MG). Graduada em Direito pela Faculdade de Direito Milton Campos (2015). Pesquisadora do Grupo de Pesquisa e Estudos em Direito do Trabalho RED - Retrabalhando o Direito, da Pontifícia Universidade Católica de Minas Gerais. Integrante da Oficina de Estudos Avançados: As interfaces entre o Processo Civil e o Processo do Trabalho - IPCPT. Advogada. E-mail: irissoier@hotmail.com 2 Pós-graduanda em Direito do Trabalho na Faculdade de Direito Milton Campos. Graduada em Direito pela Universidade de Itaúna (2016). E-mail: sarahluana93@gmail.com 
8.036/90 e 8.219/91, dando origem à Reforma Trabalhista, completará 2 (dois) anos de sua vigência.

A referida Lei trouxe em seu bojo inúmeras alterações e permissivos que, numa clara tentativa de esvaziar direitos duramente conquistados ao longo dos anos, flexibiliza normas, direitos e princípios já consolidados, sob o frágil argumento de modernização da legislação laboral.

A Lei da Reforma Trabalhista, contrariando garantias constitucionais, fez significativas alterações no campo do Direito Individual, do Direito Coletivo, bem como no plano do Direito Processual do Trabalho, não se olvidando, ainda, das mudanças no em âmbito principiológico.

Dentre as alterações promovidas no texto celetista, a Lei n. 13.467/2017 também alterou normas relativas ao trabalho da mulher, que passou a ser regulado e protegido há pouco tempo, em comparativo com o trabalho dos homens, sendo, ainda hoje, vítimas de discriminação no ambiente de trabalho.

Um exemplo disso, é que mesmo com uma leve queda na desigualdade salarial entre 2012 e 2018, as mulheres ainda ganham, em média, 20,5\% menos que os homens no país, de acordo com um estudo especial feito pelo IBGE para o Dia Internacional da Mulher, com base na Pesquisa Nacional por Amostra de Domicílios Contínua (PNAD Contínua).

Posto isto, o objetivo do presente trabalho é estudar o trabalho da mulher e as alterações realizadas pela Reforma Trabalhista, analisando se houve mitigação de direitos e tentativa de precarização das condições de trabalho.

O segundo capítulo será destinado a uma breve exposição acerca do histórico da discriminação contra a mulher no mercado de trabalho e a sua evolução, desde a inserção da mulher no mercado de trabalho na primeira Revolução Industrial até os dias atuais. Neste tópico será abordada, ainda, a importância da Constituição Federal da República de 1988 na efetivação dos direitos e garantias.

O terceiro capítulo será destinado para a análise específica das alterações promovidas pela Reforma Trabalhista sobre o trabalho da mulher, 
expondo criticamente a revogação do parágrafo único do art. 372 da CLT, revogação do art. 384 da CLT, a nova redação dada ao art. 394-A da CLT e a inserção do $\S 2^{\circ}$ do art. 396 da CLT.

No quarto capítulo será destacada o papel do Supremo Tribunal Federal (STF) no combate aos abusos legislativos pós reforma, defendendo a importância da análise concisa das questões postas sob o crivo da constitucionalidade e da convencionalidade.

No quinto capítulo será trazida a conclusão, com um breve apanhado geral sobre o estudo e resultados expostos

\section{O histórico da discriminação contra a mulher no mercado de trabalho e sua evolução}

A discriminação contra a mulher não é novidade. Desde o início dos tempos, as mulheres eram vistas como subservientes, servas de seus lares e maridos, sendo impedidas de se expressarem como cidadãs autônomas que são.

O início da participação da mulher no mercado de trabalho ocorreu na transição do capitalismo pré-industrial para o capitalismo industrial, onde as mulheres passaram a se inserir no mercado de trabalho (ABRAMO, 2007.p. 23). Após esse fenômeno na I Revolução Industrial, as mulheres voltaram a ocupar postos de trabalho de forma mais significativa durante as grandes guerras, onde os homens eram obrigados a abandonar seus postos de trabalho para defender seu país.

Após isso, no século $\mathrm{XX}$, com o aumento do uso as tecnologias, as mulheres voltaram a ocupar um número expressivo na população economicamente ativa (PEA), em razão da maior disponibilidade de tempo para o acúmulo de mais funções dentro e fora do âmbito doméstico. (CANTELLI, 2018, p. 268)

No Brasil, Bento Herculano Duarte Neto (2018, p. 162) ensina que a Constituição Imperial foi omissa com relação ao trabalho da mulher, sendo 
essa tendência seguida pela Constituição de 1891. O autor relata que o assunto foi tratado pela primeira vez na Constituição Federal de 1934, prevendo três meses de licença gestante.

A Constituição de 1946 proibiu a diferença salarial por motivo de sexo, garantiu a assistência hospitalar à gestante e previu o salário maternidade. Já a Constituição de 1967não trouxe alterações significativas, uma vez que foi editada no regime ditatorial.

A Constituição de 1988, que consagrou diversos direitos e garantias sociais, erigindo a dignidade pessoa humana como fundamento da República, será tratada separadamente, no subtópico a seguir.

Em 1960, no Brasil, quase oito em cada dez homens aptos a trabalhar buscavam os meios de sobreviver, por meio da mercantilização do trabalho, contra menos de suas em cada dez mulheres (GUIMARÃES, 2016.p.72).

Paula Oliveira Cantelli (2018, P. 268) ressalta que, no Brasil, nas décadas de 70, 80 e 90, observou-se um aumento significativo das mulheres na população economicamente ativa, chegando em 2003, a 42,7\% o percentual de mulheres inseridas no mercado de trabalho.

Esse aumento da participação da mulher no mercado de trabalho conviveu com outros fatores importantes como a queda da fecundidade, o aumento da escolaridade e as transformações na regulação dos papeis sociais de gênero. Nesse sentido, Naya Araujo Guimarães e Murillo Marschner Alves de Brito pontuam que:

De fato, até os anos 1970 a mulher brasileira que disputava posições no mundo do trabalho era majoritariamente jovem, solteira e sem filhos. Desde meados da década de 1990 ela tornou-se mais velha, casada e mãe. Vale dizer, o aumento na taxa de participação feminina passou a se ancorar no afluxo de mulheres em idades mais elevadas e/ou na tendência de que, ingressando mais jovens no mercado, dele não se retirassem quando do início da carreira reprodutiva. (2016, p. 75). 
A discriminação quanto ao trabalho da mulher pode ser observada em diversos aspectos, Bruschini, citada por Naya Araujo Guimarães e Murillo Marschner Alves de Brito, relata que

nada menos que $40 \%$ da força de trabalho feminina estava, em 1993, em posições ocupacionais que sugeriam a existência de trabalho precário; conforme dados para aquele ano, 17\% delas eram domésticas (contra 0,8\% dos homens), 13\% não recebiam qualquer remuneração e 10\% trabalhavam para consumo próprio. (2016, p. 77).

Em seu livro sobre feminismo, Marcia Tiburi pontua que

Desde que nasce, não é um exagero dizer, uma menina está condenada a um tipo de trabalho que se parece muito com a servidão que, em tudo, é diferente do trabalho remunerado ou do trabalho que se pode escolher dependendo da classe social à qual se pertence. Em muitos contextos, lugares, países e culturas, meninas e jovens, adultas e idosas trabalharão para seu pai, irmãos, para o marido, para os filhos. Serão, apenas por serem mulheres, condenadas ao trabalho braçal dentro de casa, a serviço de outros que não podem ou não querem trabalhar como elas. (2018, p. 14).

Não obstante a afirmação seja dura e reflita uma realidade para a qual muitas vezes a sociedade feche os olhos, não se pode negar dados estatísticos, capazes de demonstrar que, ainda hoje, as mulheres acumulam mais trabalhos que os homens em âmbito doméstico e remunerado, como demonstra pesquisa realizada pelo Instituto Brasileiro de Geografia e Estatística (IBGE) entre 2003 e 2011, sendo a das mulheres de 58,5 horas e dos homens de 52,7 horas.

Ainda segundo dados do IBGE, no ano de 2018, o rendimento médio das mulheres ocupadas com idade entre 25 e 49 anos foi de $R \$ 2.050$ (dois mil e cinquenta reais), equivalendo a $79,5 \%$ do recebido pelos homens - R $\$ 2.579$ (dois mil quinhentos e setenta e nove reais) nesse mesmo grupo etário. 
Se além do gênero for considerada a cor ou raça, a proporção de rendimento médio da mulher branca ocupada em relação ao do homem branco ocupado passa a ser de $76,2 \%$, sendo menor que essa razão entre mulher e homem de cor preta ou parda que é 80,1\%3.

A discriminação ainda está presente de acordo com a ocupação exercida. Para os trabalhadores dos serviços domésticos em geral o salário das mulheres equivalia a 95,0\% do salário dos homens em 2018; já para professores do ensino fundamental essa diferença era de $84,0 \%$; entre os profissionais das ciências e intelectuais, não obstante as mulheres tinham participação majoritária correspondendo a $63,0 \%$ da mão de obra, ainda assim recebiam $64,8 \%$ do rendimento dos homens.

Observe-se que a discriminação contra as mulheres no mercado de trabalho também assola as ocupações com maior nível de instrução, refletindo rendimentos desiguais. Entre os professores de universidades e do ensino superior, o rendimento das mulheres equivalia a $82,6 \%$ do recebido pelos homens; para ocupações como médicos especialistas e advogados, a diferença se mostra ainda maior entre os rendimentos de mulheres e homens, com percentuais de $71,8 \%$ e $72,6 \%$, respectivamente.

De toda forma, a discriminação contra a mulher está presente em várias épocas e em diversos setores do mercado de trabalho, podendo ser observada desde a inserção da mulher na população economicamente ativa até os dias de hoje.

\subsection{O papel da Constituição Federal da República de 1988}

Como símbolo de redemocratização, após duas décadas de governo ditatorial, a Constituição Federal da República de 1988, além de reconhecer a importância da cultura, do meio ambiente e da participação do povo na

\footnotetext{
3 Segundo Nadya Araujo Guimarães e Murillo Marschner Alves de Brito (2016, p. 73), o processo de mercantilização do trabalho feminino se expressa de forma diferente entre brancos e não brancos. Segundo os autores, brancos têm uma propensão mais elevada ao engajamento no mercado do que não brancos, sejam homens ou mulheres.
} 
elaboração de leis, garantiu em seu corpo direitos fundamentais em diversas áreas como saúde, educação, relações consumeristas e relações de trabalho.

Além disso, a Constituição Federal erigiu princípios gerais, de observância obrigatória, a fim de diminuir a discriminação, a desigualdade de direitos e o desrespeito à dignidade humana, colocando o ser humano no centro dos direitos e garantias.

No universo jurídico, os princípios surgem primeiramente como proposição ideal, sendo esta sua função tradicional. Tanto é que para que certo ramo do Direito tenha sua autonomia científica reconhecida, se busca a indicação de seus princípios específicos. (2018, p. 59).

Sabe-se que os princípios são enunciações normativas de valor genérico, que condicionam e orientam a compreensão do ordenamento jurídico, quer para a sua aplicação e integração, quer para a elaboração de novas normas.

Para fins didáticos, Maurício Godinho Delgado atribui aos princípios três papéis essenciais: o primeiro como proposições ideais (princípios descritivos), o segundo como fonte supletiva (princípios normativos subsidiários) e o terceiro seria o caráter normativo próprio dos princípios.

Os princípios têm uma tríplice função. Primeira, a função interpretativa, da qual são um elemento de apoio. Segunda, a função de elaboração do direito do trabalho, já que auxiliam o legislador. Terceira, a função de aplicação do direito, na medida em que servem de base para o juiz sentenciar. (2019, p. 223-224)

O princípio da dignidade da pessoa humana, cujo amparo se encontra no art. $1^{\circ}$, III, da CF, tem seu conceito central espalhado em diversos arts. da Constituição Federal, com a função de garantir o mínimo de direitos ao cidadão.

O princípio da vedação ao retrocesso, extraído do caput do art. $7^{\circ}$ da $\mathrm{CF}$ estabelece que direitos aos trabalhadores urbanos e rurais que visem à melhoria da sua condição social, sendo vedado o retrocesso social já 
positivado. Ou seja, a atuação do legislador não pode ser em malefício aos direitos já reconhecidos e conquistados.

$\mathrm{O}$ art. $5^{\mathrm{o}}$ em seu caput sedimenta o princípio da igualdade, prevendo que todos são iguais perante a lei, garantindo, além disso, no inciso I do mesmo artigo, que homens e mulheres são iguais em direitos e obrigações.

Ainda, reconhecendo um padrão discriminatório histórico e a necessidade de reequilibrar a comprovada desigualdade entre o trabalho da mulher e do homem, a Constituição prevê proteção do mercado de trabalho da mulher, mediante incentivos específicos (art. $7^{\circ}, \mathrm{XX}$ ), buscando mitigar as diferenças salariais, a segregação no exercício de funções e qualquer outra discriminação em razão do gênero.

Além disso, a Constituição Federal prevê em seu art. $5^{\circ}, \S 2^{\circ}$ que os direitos e garantias contidos na Carta Maior "não excluem outros decorrentes do regime e dos princípios por ela adotados, ou dos tratados internacionais em que a República Federativa do Brasil seja parte", autorizando a importação de normas constantes nos diplomas internacionais, a fim de aumentar o rol protecionista garantido ao ser humano.

Considerando que ao redor do mundo existem inúmeras situações de desigualdade, não apenas de gênero como o presente caso, mas de raça e sociais, com indivíduos sujeitos a condições de trabalho rodeada por miséria e privações, faz-se necessária a regulamentação de alguns pontos básicos para que seja possível a conservação da paz, da harmonia e da dignidade da pessoa humana, cuja conquista se relaciona diretamente com a manutenção da liberdade individual, bem como da integridade física e psíquica.

A Declaração Universal de Direitos Humanos traz uma concepção ampla de Direitos Humanos, igualando a importância entre os direitos civis e políticos aos econômicos, sociais e culturais. O diploma traz ainda ferramentas normativas destinadas à afirmação do direito fundamental ao trabalho digno e à proteção dos trabalhadores.

Ainda no âmbito das normas internacionais, a Declaração Universal dos Direitos do Homem, de 1948, transformou os direitos humanos em um 
tema global e universal, traçando uma diretiva política voltada para a positivação dos Direitos Humanos.

Nesse contexto, o surgimento da Organização Internacional do Trabalho4, em 1919, veio como uma resposta aos movimentos que pressionavam o Estado para a criação de mecanismos de proteção aos trabalhadores, a fim de assegurar bases sólidas para a paz mundial e obter melhores condições humanas para a classe trabalhadora.

Ressalte-se que, além dos princípios elencados acima, a jurisprudência internacional adota outros para a concretização dos direitos humanos, como o princípio da interpretação pro homine e o princípio da supremacia da norma mais favorável ao indivíduo.

O primeiro princípio, o da interpretação pro homine, estabelece que a interpretação das normas jurídicas deve ser realizada em atenção à proteção dada aos indivíduos, prevendo que, no conflito de normas, deverá prevalecer a norma que garantir e proteger os direitos humanos.

Da leitura do aludido princípio, tem-se que a interpretação das leis deverá ser restritiva quando limitarem direitos humanos e extensiva quando os ampliarem, aplicando as normas sempre no sentido de proteger o indivíduo.

Outro princípio que guarda íntima relação com o princípio da interpretação pro homine é o princípio da supremacia da norma mais favorável ao indivíduo, que prevê que, na hipótese de colisão de normas de direito interno e internacional que versem sobre direitos humanos, prevalecerá aquela que for mais favorável à pessoa humana.

Ressalte-se que “o Direito do Trabalho é uma das vertentes dos Direitos Humanos, cuja dimensão ética requer aglutinação dos conceitos de dignidade, de cidadania e de justiça social” (DELGADO; DELGADO, 2018, p. 67).

Observe-se que em diversos aspectos a Constituição Federal buscou fundamentar a igualdade de direitos, a não discriminação, a proteção do trabalho da mulher, o reconhecimento de diplomas internacionais ratificados integrando o sistema das Nações Unidas como uma das suas agências especializadas. 
pelo Brasil para integrar o rol protecionista. Tudo a fim de garantir uma vida digna ao ser humano.

A Lei n. 13.467/2017, que deu origem à Reforma trabalhista, pareceu ignorar todo o esforço constitucional na busca de melhoria das condições sociais do trabalhador, promovendo alterações no texto da Consolidação das Leis do Trabalho (CLT), capazes de acentuar ainda mais a discriminação contra a mulher, conforme será abordado adiante.

\section{A reforma trabalhista e o trabalho da mulher}

\subsection{Revogação do parágrafo único do art. 372 da CLT}

$\mathrm{O}$ art. 372 caput prevê que "os preceitos que regulam o trabalho masculino são aplicáveis ao trabalho feminino, naquilo em que não colidirem com a proteção especial instituída por este Capítulo.” Já o revogado parágrafo único estabelecia que "não é regido pelos dispositivos a que se refere este artigo o trabalho nas oficinas em que sirvam exclusivamente pessoas da família da mulher e esteja esta sob a direção do esposo, do pai, da mãe, do tutor ou do filho".

Embora a Reforma Trabalhista tenha realizado algumas alterações polêmicas, questionáveis sob o crivo da constitucionalidade e da convencionalidade, a revogação do parágrafo único do art. 372 não foi uma delas. Isso porque, a disposição ali constante já não vigorava no ordenamento jurídico brasileiro, por não ter sido recepcionada pela Constituição Federal.

Sobre a revogação do dispositivo, Maurício Godinho Delgado e Gabriela Neves Delgado esclarecem:

Ora, o parágrafo único do art. 372 da CLT encontrava-se em posição obviamente antitética ao comando emanado pelo art. $7^{\circ}, \mathrm{XX}$, da Constituição da República, razão pela qual não foi recepcionado, sem qualquer dúvida, também por esse inciso XX do art. $7^{\circ}$. É que, ao invés de fixar proteção e 
incentivos específicos ao mercado de trabalho da mulher, antigo parágrafo único corroborava manifestas desproteção e, até mesmo, discriminação a elas dirigidas. (2018, p. 152).

Além disso, conforme já mencionado, o art. $5^{\circ}$ caput e inciso I, da CF preveem a igualdade de direitos entre o homem e a mulher, não havendo mais espaço para disposições como essa.

\subsection{Revogação do art. 384 da CLT}

Outra alteração relacionada ao trabalho da mulher pela Lei $\mathrm{n}$. 13.467/2017, foi a revogação do art. 384 da CLT, que previa uma pausa de 15 minutos antes do início do período extraordinário de trabalho.

O dispositivo previa: "art. 384 - Em caso de prorrogação do horário normal, será obrigatório um descanso de 15 (quinze) minutos no mínimo, antes do início do período extraordinário do trabalho".

Conforme já exposto no presente estudo, o art. $7^{\circ}, \mathrm{XX}$ da $\mathrm{CF}$, prevê proteção do mercado de trabalho da mulher, mediante incentivos específicos, nos termos da lei. Acredita-se que a disposição revogada se tratava de um desses incentivos específicos, citados na Constituição.

Além disso, a Convenção n. 155 da OIT, ratificada pelo Brasil por meio do Decreto n. 1.254 de 29 de setembro de 1994, garante segurança e saúde aos trabalhadores, bem como um meio ambiente de trabalho equilibrado.

Ao suprimir o intervalo de 15 minutos previstos para as mulheres, o legislador reformista vai de encontro não apenas a preceito constitucional, mas a disposição convencional, ratificada pelo Brasil.

Conforme bem pontua Paula Oliveira Cantelli:

O intervalo intrajornada especial de 15 minutos, destinado às mulheres, tem um objetivo específico: restabelecer a capacidade (física e mental) de trabalho, 
antes do início do labor extraordinário, resguardando a saúde da trabalhadora

e, de modo geral, reduzindo os riscos de acidente de trabalho.(2018, p. 274).

Não raramente os acidentes do trabalho acontecem no período de sobrejornada, razão pela qual, entende-se que ao invés de revogar o benefício especial garantido às mulheres, o legislador deveria ter estendido aos homens, para ser possível que se refaçam física e mentalmente antes do início das horas extras.

\subsection{Nova redação do art. 394-A da CLT}

Outra alteração promovida pela Lei n. 13.467/2017 relacionada ao trabalho da mulher, foi a nova redação dada ao art. 394-A da CLT. A antiga redação do dispositivo previa: "a empregada gestante ou lactante será afastada, enquanto durar a gestação e a lactação, de quaisquer atividades, operações ou locais insalubres, devendo exercer suas atividades em local salubre."

A Reforma Trabalhista, entretanto, alterou a redação do artigo 394-A, inserindo três incisos e 2 parágrafos (os $\S \S 2^{\circ}$ e $3^{\circ}$, já que o $1^{\circ}$ foi vetado antes da entrada em vigor da Lei n. 13.467/2017.

A nova redação do conjunto normativo do art. 394-A da CLT, passou a ser a seguinte:

Art. 394-A. Sem prejuízo de sua remuneração, nesta incluído o valor do adicional de insalubridade, a empregada deverá ser afastada de:

I - atividades consideradas insalubres em grau máximo, enquanto durar a gestação;

II - atividades consideradas insalubres em grau médio ou mínimo, quando apresentar atestado de saúde, emitido por médico de confiança da mulher, que recomende o afastamento; 
III - atividades consideradas insalubres em qualquer grau, quando apresentar atestado de saúde, emitido por médico de confiança da mulher, que recomende o afastamento.

$\S 1^{\circ}(\mathrm{VETADO})$

$\S 2^{\circ}$ Cabe à empresa pagar o adicional de insalubridade à gestante ou à lactante, efetivando-se a compensação, observado o disposto no art. 248 da Constituição Federal, por ocasião do recolhimento das contribuições incidentes sobre a folha de salários e demais rendimentos pagos ou creditados, a qualquer título, à pessoa física que lhe preste serviço.

$\S 3^{\circ}$ Quando não for possível que a gestante ou a lactante afastada nos termos do caput deste artigo exerça suas atividades em local salubre na empresa, a hipótese será considerada como gravidez de risco e ensejará a percepção de salário-maternidade, nos termos da Lei no 8.213, de 24 de julho de 1991, durante todo o período de afastamento.

O deputado Rogério Marinho, relator do Projeto de Lei n. 6.787/2016, que deu origem à Lei da Reforma Trabalhista, justificou a alteração da redação do art. 394-A da CLT da seguinte forma:

Quando da sanção da lei que acrescentou a atual redação do art. 394-A à CLT, pensou-se que se estava adotando uma medida protetiva à mulher. Reconhecemos a boa intenção contida na redação atual do artigo, mas o que aparenta ser uma medida protetiva à mulher acaba por lhe ser prejudicial.

Esse dispositivo tem provocado situações de discriminação ao trabalho da mulher em locais insalubres, tanto no momento da contratação quanto na manutenção do emprego. Essa situação é marcante em setores como o hospitalar, em que todas as atividades são consideradas insalubres, o que já tem provocado reflexos nos setores de enfermagem, por exemplo, com o desestímulo à contratação de mulheres. Além disso, ao afastar a empregada gestante ou lactante de quaisquer atividades, operações ou locais insalubres, há, de imediato, uma redução salarial, pois ela deixa de receber o respectivo adicional, refletindo, inclusive, no benefício da licença-maternidade a que faz jus. (2016, p. 47-48). 
Os abusos cometidos pelo legislados neste dispositivo são tantos, faz-se necessário enumerá-los. Primeiramente, analisar-se-á as justificativas constantes na exposição de motivos da Reforma Trabalhista.

Os trechos destacados sugerem pelo Relator Deputado Rogério Marinho que a norma, mascarada pelo viés protetivo, poderia ser prejudicial à mulher, visto que a manutenção do dispositivo provocaria discriminação contra a mulher desde a contratação até a sua manutenção no trabalho.

Sem razão, contudo, o deputado. Primeiro, porque a Constituição Federal autoriza em seu art. $7^{\circ}, \mathrm{XX}$, a proteção do trabalho da mulher mediante incentivos específicos, sendo a disposição revogada pela Reforma Trabalhista, uma delas.

Além disso, o art. $5^{\circ}$, I da CF prevê expressamente que os homens e mulheres são iguais em direitos e obrigações, não podendo, portanto, a mulher se discriminada no trabalho por gozar de uma garantia legal, sob pena de afronta direta à Constituição.

Ainda, dentre os direitos sociais garantidos no art. $6^{\circ}$ da $\mathrm{CF}$, estão listados expressamente a saúde, a proteção à maternidade e à infância. No mesmo sentido, o art. 201, II, da CF garante que a previdência social seja responsável pela proteção à maternidade, especialmente à gestante.

Sendo assim, resta claro que as disposições constantes na exposição de motivos pelo Relator da Reforma Trabalhista, estão distantes da Constituição, sendo questionáveis sob o crivo da constitucionalidade.

Além disso, a nova redação dada ao artigo 394-A da CLT vai de encontro à Convenção n. 103, da OIT, ratificada pelo Brasil por meio do Decreto n. 58.820/66, que traz disposições de amparo à maternidade. Da mesma forma, viola as disposições da Convenção n. 183 da OIT, também sobre proteção à maternidade.

Não bastasse isso, a alteração promovida pela Lei n. 13.467/2017 não se mostra compatível com as disposições dos artigos I, II e XXV da DUDH, que preveem expressamente que todos os seres são iguais em direitos e em 
dignidade, podendo gozar de seus direitos e liberdades, sem distinção de raça, seco, cor, religião ou diferença de qualquer outra natureza, bem como a proteção à família, proteção à maternidade e à infância.

A Associação Nacional dos Magistrados da Justiça do Trabalho

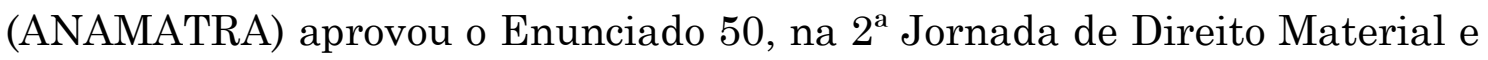
Processual do Trabalho, prevendo:

Enunciado 50. Trabalhadora gestante e lactante. art. 394-A da CLT

A autorização legal permitindo o trabalho da gestante e lactante em ambiente insalubre é inconstitucional e inconvencional porque violadora da dignidade humana, do direito à redução dos riscos inerentes ao trabalho, da proteção integral ao nascituro e à criança e do direito social à saúde. Ademais, o meio ambiente do trabalho saudável é direito fundamental garantido pela Constituição da república, revestido de indisponibilidade absoluta. incidência dos arts. $1^{\circ}$, III; $6^{\circ} ; 7^{\circ}$, XXII; 196; 200;201, II; 203, I; 225; 226 e 227 da Constituição Federal; Convenção 103 e 183 da OIT; arts. 25, I e II da DUDH.

Frente à todas as violações expressas, não restou outro caminho senão a propositura da Ação Direta de Inconstitucionalidade (ADI) n. 5938, pela Confederação Nacional dos Trabalhadores Metalúrgicos, em 26 de abril de 2018.

Em 30 de abril de 2019, o Ministro Alexandre de Moraes deferiu o pedido liminar para suspender a eficácia da expressão "quando apresentar atestado de saúde, emitido por médico de confiança da mulher, que recomende o afastamento", contida nos incisos II e III do art. 394-A da CLT, inseridos pelo art. $1^{\circ}$ da Lei n. 13.467/2017.

Em 29 de maio de 2019, o Tribunal Pleno do STF julgou procedente, por unanimidade, a ADI para declara a inconstitucionalidade da expressão "quando apresentar atestado de saúde, emitido por médico de confiança da mulher, que recomende o afastamento", contida nos incisos II e III do art. 394- 
A da CLT, inseridos pelo art. $1^{\circ}$ da Lei n. 13.467/2017, sendo o acórdão publicado em 23 de setembro de 2019 .

O Ministro Relator Alexandre de Moraes iniciou seu voto observando que, após a alteração legal, a norma passou a impor às grávidas e às lactantes o ônus de apresentar atestado de saúde como condição para o afastamento, sujeitando a trabalhadora a maior embaraço para o exercício de seus direitos, sobretudo para aquelas que não têm acesso à saúde básica para conseguir o atestado.

Ainda segundo o relator, a norma proposta pela Lei n. 13.467/2017 estava em desacordo com diversos direitos consagrados na Constituição Federal e deles derivados, entre eles a proteção à maternidade, o direito à licença-maternidade e a segurança no emprego assegurada à gestante, além de normas de saúde, higiene e segurança.

Por fim, entendeu que a proteção da mulher grávida ou da lactante em relação ao trabalho insalubre caracteriza-se como direito social protetivo tanto da mulher quanto da criança.

Ainda, quanto à justificativa apresentada para a redação dada ao conjunto normativo do art. 394-A da CLT, o Ministro Relator entendeu não proceder o argumento de que a declaração de inconstitucionalidade poderia acarretar retração da participação da mulher no mercado de trabalho, afirmando expressamente que "eventuais discriminações serão punidas nos termos da lei, e o próprio texto constitucional determina de maneira impositiva a proteção ao mercado de trabalho da mulher mediante incentivos específicos",

Dessa forma, ante o reconhecimento da inconstitucionalidade da norma contida no art. 394-A da CLT, pelo STF, a redação do dispositivo passa a ser a seguinte:

Art. 394-A. Sem prejuízo de sua remuneração, nesta incluído o valor do adicional de insalubridade, a empregada deverá ser afastada de: 
I - atividades consideradas insalubres em grau máximo, enquanto durar a gestação;

II - atividades consideradas insalubres em grau médio ou mínimo, durante a gestação;

III - atividades consideradas insalubres em qualquer grau, durante a lactação.

Observe-se que, não mais se fala em apresentação de atestado médico pela mulher, devendo esta, se gestante ou lactante, ser afastada de atividades insalubres, com a manutenção do pagamento do referido adicional.

\subsection{Inserção do $§ 2^{\circ}$ do art. 396 da CLT}

Por fim, a última alteração promovida na CLT pela Lei da Reforma Trabalhista sobre o trabalho da mulher, foi a inserção do parágrafo $2^{\circ}$ do art. 396 da CLT:

Art. 396. Para amamentar seu filho, inclusive se advindo de adoção, até que este complete 6 (seis) meses de idade, a mulher terá direito, durante a jornada de trabalho, a 2 (dois) descansos especiais de meia hora cada um.

$\S 1^{\circ}$ Quando o exigir a saúde do filho, o período de 6 (seis) meses poderá ser dilatado, a critério da autoridade competente.

$\S 2^{\circ}$ Os horários dos descansos previstos no caput deste artigo deverão ser definidos em acordo individual entre a mulher e o empregador.

O intervalo especial e remunerado previsto no artigo 396 está em plena consonância com as disposições da Convenção 183 da OIT, que versa sobre a proteção à maternidade.

$\mathrm{Na}$ mesma linha, a Convenção 103, artigo 5, estabelece que "se a mulher amamentar seu filho, será autorizada a interromper seu trabalho com esta finalidade durante um ou vários períodos cuja duração será fixada pela legislação nacional.” 
Sobre a alteração, sabe-se que, na prática, os intervalos já eram negociados entre empregador e empregada, a fim de possibilitar que as necessidades desta se adequassem às daquele.

A Lei n. 13.467/2017, entretanto, preferiu explicitar o que já tende a ser prática efetiva durante a relação de emprego, a definição consensual sobre o melhor horário para o cumprimento dos intervalos (DELGADO; DELGADO, 2018, p. 155).

Ressalte-se que a possibilidade de negociação por parte do trabalhador, sempre estará maculada pela necessidade do trabalho, que pode vir a acentuar as condições de precarização das condições de trabalho e de direitos, em prejuízo à dignidade (VIANA; TEODORO, 2017, online).

\section{O papel do Supremo Tribunal Federal (STF) no combate aos abusos legislativos pós reforma}

As alterações realizadas na CLT por meio da Lei n. 13.467/2017, que deu origem à Reforma Trabalhista, foram tão polêmicas, que 15 Ações Diretas de Inconstitucionalidade (ADIs) foram propostas no STF, para questionar a constitucionalidade das normas já em vigor.

Tantas são os questionamentos levantados que o STF já afetou temas relativos à Lei n. 13.467/2017, bem como já invalidou a norma que permitia trabalho de grávidas e lactantes em atividades insalubres, conforme exposto no tópico anterior.

Mais recentemente, o ministro Gilmar Mendes, do STF, determinou a suspensão nacional de todos os processos que discutam validade de norma coletiva que limite ou restrinja direito trabalhista não assegurado constitucionalmente5. 
Essas alterações realizadas no mundo jurídico pelo STF são realizadas por meio do controle de constitucionalidade que, segundo Manoel Gonçalves Ferreira Filho:

é a verificação da adequação de um ato jurídico (particularmente da lei) à Constituição. Envolve a verificação tanto dos requisitos formais - subjetivos, como a competência do órgão que o editou - objetivos, como a forma, os prazos, o rito, observados em sua edição - quanto dos requisitos substanciais respeito aos direitos e às garantias consagrados na Constituição - de constitucionalidade do ato jurídico. (2012, p. 51).

Quanto ao momento em que se intervém, o controle de constitucionalidade poderá ser preventivo ou repressivo. Aquele opera antes que o ato, particularmente a lei, se aperfeiçoe; este depois de perfeito o ato, de promulgada a lei.(FERREIRA FILHO, 2012, p. 52) O preventivo é reservado ao presidente da república por meio da possibilidade do exercício de veto. Já o controle repressivo é confiado ao poder judiciário.

O controle realizado por meio do judiciário pode ser difuso ou concentrado. Há controle difuso quando a qualquer juiz é dado apreciar a alegação de inconstitucionalidade. É concentrado o controle toda vez que a competência para julgar a questão de constitucionalidade é reservada a um único órgão.

O art. 102, I, a, da CF prevê a ação direta de inconstitucionalidade, que poderá ser usada para fins de se declarar a inconstitucionalidade de uma lei ou de um ato normativo federal ou estadual.

Trata-se, aqui, de controle principal, que exerce exclusivamente o Supremo Tribunal Federal (controle concentrado) em ação que era proposta pelo Procurador-Geral da República privativamente, no direito anterior, mas que hoje também o pode ser pelo Presidente da República, pela Mesa do Senado Federal, pela Mesa da Câmara dos Deputados, pela Mesa da Assembleia Legislativa, ou da Câmara Legislativa do Distrito Federal, por Governador de 
Estado, ou do Distrito Federal, pelo Conselho Federal da Ordem dos Advogados do Brasil, por partido político com representação no Congresso Nacional e por confederação sindical ou entidade de classe de âmbito nacional. (FERREIRA FILHO, 2012, p. 55).

Dentre as ADIs em tramitação, ainda restam pendentes de manifestação pelo STF, a ADI n. 5867, que trata da atualização do depósito recursal por meio da Taxa Referencial (TR); as ADIs ns. 5870, 6050, 6069, 6082, que tratam sobre indenização por danos morais; a ADI n. 6021, que versa sobre a atualização dos débitos trabalhistas por meio da TR; a ADI n. 5994, que trata da jornada 12x36; a ADI n. 5766, que versa sobre a gratuidade de justiça; as ADIs ns. 5806, 5826, 5829 e 6154 que tratam sobre o trabalho intermitente; a ADI n. 6142 que dispõe acerca da homologação da dispensa sem assistência dos sindicatos; e a ADI n. 6002, que trata do valor do pedido na reclamação trabalhista.

Da mesma forma que vários dispositivos da Lei que deu origem à Reforma Trabalhista podem ser questionadas à luz da Constituição Federal, também podem ser objeto de questionamento se analisadas em consonância com os tratados internacionais ratificados pelo Brasil, abrindo possibilidade para o controle da aplicação das normas de direitos sociais e fundamentais, por meio do exercício do controle de convencionalidade pelos juízes e tribunais pátrios.

Assim como o exercício do controle de constitucionalidade, que se trata de um mecanismo de correção de determinado ato ou norma para a sua conformidade com a Constituição Federal, cabe ao STF o exercício do controle de convencionalidade, que por sua vez, trata-se de um processo de verificação da compatibilidade ou incompatibilidade de normas jurídicas de um Estado aos tratados internacionais dos quais seja signatário.

Conforme exposto no presente trabalho, as disposições sobre o trabalho da mulher previstas na Lei n. 13.467/2017 vão de encontro às Convenções 155, 103, 183, além de contrariar dispositivos da DUDH, sendo o exame de 
compatibilidade com essas normas tão necessário quanto o controle de constitucionalidade exercido de forma concentrada pelo STF.

\section{Conclusão}

Como bem pontua Marcia Tiburi "não há nada mais importante na vida do que aprender a pensar, e não se aprende a pensar sem aprender a perguntar pelas condições e pelos contextos nos quais estão situados nossos objetos de análise e de interesse." (2018, p. 10)

Diferente não poderia ocorrer com o trabalho da mulher, o questionamento das raízes da discriminação, das condições de trabalho e dos contextos em que muitas trabalhadoras estão expostas vão influenciar diretamente nas formas de trabalho a que elas se submeterão, refletindo nos resultados que temos hoje, mulheres acumulando uma maior carga horária de trabalho, com salários menores que os dos homens e ainda dominando os índices de desemprego.

Conforme exposto no presente trabalho, a discriminação contra a mulher no mercado de trabalho vem de muitos anos, levando um longo processo para se estender às mulheres direitos já garantidos aos homens nas Constituições anteriores à de 1988.

Ocorre que, mesmo com a Constituição Federal da República garantindo expressamente a igualdade entre homens e mulheres, bem como a proteção ao trabalho feminino, ainda assim, os dados não mentem. As mulheres acumulam maior carga de trabalho, ganham menos e sofrem mais com a discriminação.

A Lei n. 13.467/2017, ao invés de reforçar a necessidade de garantias aos trabalhadores, com seu manto precarizador, veio para agravar ainda mais a situação do trabalho da mulher, revogando o parágrafo único do art. 372 da CLT, do art. 384 da CLT, dando nova redação ao art. 394-A da CLT e inserindo do $\S 2^{\circ}$ do art. 396 da CLT. 
A alteração mais significativa promovida pela Reforma Trabalhista foi a alteração da redação do art. 394-A da CLT, que autorizava o trabalho de gestantes e lactantes em condições insalubres.

Essa disposição, entretanto, foi declarada inconstitucional pelo STF no julgamento da ADI n. 5938, sob o argumento de que a redação dada ao dispositivo da CLT feria garantias constitucionais de proteção à maternidade, o direito à licença-maternidade e a segurança no emprego assegurada à gestante, além de normas de saúde, higiene e segurança.

A declaração de inconstitucionalidade da nova redação do art. 394-A da CLT reforça a tese defendida no presente estudo de que cabe ao STF o controle concentrado de constitucionalidade, que se trata de um mecanismo de correção de determinado ato ou norma para a sua conformidade com a Constituição Federal, bem como o controle de convencionalidade, que por sua vez, trata-se de um processo de verificação da compatibilidade ou incompatibilidade de normas jurídicas de um Estado aos tratados internacionais dos quais seja signatário.

Assim, espera-se que, o ordenamento jurídico esteja mais amarrado com dignidade da pessoa humana, garantindo aos trabalhadores, homens e mulheres, um trabalho e uma existência digna.

\section{Referências}

ABRAMO, Laís Wendel. A inserção da mulher no mercado de trabalho: uma força de trabalho secundária?.2007. Dissertação Doutorado em Sociologia) Faculdade de Filosofia, Letras e Ciências Humanas da Universidade de São Paulo, São Paulo, 2007.

BRASIL. [Constituição (1988)]. Constituição da República Federativa do Brasil de 1988: Nós, representantes do povo brasileiro, reunidos em Assembleia Nacional Constituinte para instituir um Estado Democrático, destinado a assegurar o exercício dos direitos sociais e individuais, [...]. 
Brasília, DF: Planalto, [2019]. Disponível em:

$<$ http://www.planalto.gov.br/ccivil_03/constituicao/constituicao.htm>. Acesso em 12 set. 2019.

BRASIL. Decreto n. 1.254, de 29 de setembro de 1994. Promulga a Convenção número 155, da Organização Internacional do Trabalho, sobre Segurança e Saúde dos Trabalhadores e o Meio Ambiente de Trabalho, concluída em Genebra, em 22 de junho de 1981. Brasília, DF: Presidência da República [2019]. Disponível em:

$<$ http://www.planalto.gov.br/ccivil_03/decreto/1990-1994/D1254.htm>.

Acesso em: 21 set. 2019.

BRASIL. Decreto n. 58.820, de 14 de julho de 1966. Promulga a Convenção $\mathrm{n}^{0} 103$ sobre proteção à maternidade. Brasília, DF: Presidência da República [2019]. Disponível em: <http://www.planalto.gov.br/ccivil_03/decreto/19501969/D58820.htm>. Acesso em: 21 set. 2019.

BRASIL. Decreto-Lei n. 5.452, de $1^{\circ}$ de maio de 1943. Aprova a Consolidação das Leis do Trabalho. Rio de Janeiro, RJ: Presidência da República [2019]. Disponível em: <http://www.planalto.gov.br/ccivil_03/decretolei/del5452.htm>. Acesso em: 12 set. 2019.

BRASIL. Lei n. 13.467, de 13 de julho de 2017. Altera a Consolidação das Leis do Trabalho (CLT), aprovada pelo Decreto-Lei no 5.452, de 1o de maio de 1943, e as Leis nos 6.019, de 3 de janeiro de 1974, 8.036, de 11 de maio de 1990, e 8.212, de 24 de julho de 1991, a fim de adequar a legislação às novas relações de trabalho. Brasília, DF: Presidência da República [2019].

Disponível em: <http://www.plan alto.gov.br/ccivil_03/_ato20152018/2017/lei/113467.htm>. Acesso em: 12 set. 2019. 
BRASIL. Medida Provisória $n^{\circ}$ 808, de 14 de novembro de 2017. Altera a Consolidação das Leis do Trabalho - CLT, aprovada pelo Decreto-Lei ${ }^{0}{ }^{\circ}$ 5.452, de $1^{\circ}$ de maio de 1943. Brasília, DF: Presidência da República [2019]. Disponível em: <http://www.planalto.gov.br/ccivil_03/_Ato20152018/2017/Mpv/mpv808.htm>. Acesso em: 12 set. 2019.

BRASIL. Supremo Tribunal Federal. ADI 5938. Ação Direta de Inconstitucionalidade. Número único: 0069830-37.2018.1.00.0000. Requerente: Confederaão Nacional dos Trabalhadores Metalurgicos. Relator: Min. Alexandre Moraes, 26 abr 2018. Brasília: STF, [2019]. Disponível em: $<$ http://portal.stf.jus.br/processos/detalhe.asp?incidente $=5447065>$. Acesso em: 23 set. 2019.

CANTELLI, Paula Oliveira. A reforma trabalhista e o trabalho da mulher. In: FARIA, Fernanda Nigri; TOSTES, Laura Ferreira Diamantino. Aportes teóricos para a aplicação do direito do trabalho após a reforma trabalhista. Belo Horizonte: Arraes, 2018.p. 265-284.

DELGADO, Maurício Godinho; DELGADO, Gabriela Neves. A reforma trabalhista no Brasil: com os comentários à Lei 13.467/2017. 2. ed. São Paulo: Ltr, 2018.

DELGADO, Maurício Godinho. Curso de Direito do Trabalho. 18 ed. São Paulo: Ltr. 2019.

DUARTE NETO, Bento Herculano. O trabalho da gestante em atividades insalubres e as inovações introduzidas pela reforma trabalhista. In: HORTA, Denise Alves; et al. Direito do trabalho e processo do trabalho: reforma trabalhista principais alterações. Atualizado de acordo com a MP n. 808 de 14 de novembro de 2017. São Paulo, LTr, 2018.p. 162-166. 
EM 2018, mulher recebia 79,5\% do rendimento do homem. 04/07/2019. Estatísticas Sociais. Agência IBGE Notícias. Disponível em: $<$ https://agenciadenoticias.ibge.gov.br/agencia-sala-de-imprensa/2013agencia-de-noticias/releases/23923-em-2018-mulher-recebia-79-5-dorendimento-do-homem>. Acesso em: 13 set. 2019.

FERREIRA FILHO, Manoel Gonçalves. Curso de Direito Constitucional. 38. ed. rev. atual. São Paulo: Saraiva, 2012.

GANDRA, Alana. IBGE: mulheres ganham menos que homens mesmo sendo maioria com ensino superior. 7 mar. 2018. Agência Brasil. Rio de Janeiro. Disponível em: <http://agenciabrasil.ebc.com.br/geral/noticia/201803/ibge-mulheres-ganham-menos-que-homens-mesmo-sendo-maioria-comensino-superior>. Acesso em: 17 set. 2019.

GARCIA, Gustavo Filipe Barbosa. Curso de Direito do Trabalho. 12 ed. Rio de Janeiro. Forense. 2018.

GUIMARÃES, Nadya Araujo; BRITO, Murillo Marschner Alves de. Mercantilização no feminino: a visibilidade. In: ABREU, Alice Rangel de Paiva; HIRATA, Helena; LOBARDI, Maria Rosa (Org.). Gênero e trabalho no Brasil e na França: perspectivas interseccionais. 1.ed. São Paulo: Boitempo, 2016.p.71-82.

HIRATA, Helena; KERGOAT, Daniele. Divisão sexual do trabalho profissional e doméstico: Brasil, França, Japão. In: COSTA, Albertina de Oliveira; et al (org.). Mercado de trabalho e gênero: comparações internacionais. Rio de Janeiro: Editora FGV, 2008.p. 263-277 
INSTITUTO BRASILEIRO DE GEOGRAFIA E ESTATÍSTICA. Pesquisa Mensal de Emprego - PME. Mulher no mercado de trabalho: perguntas e respostas. Rio de Janeiro: IBGE, 2012. Disponível em:

<https:/ww2.ibge.gov.br/home/estatistica/indicadores/trabalhoerendimento/ pme_nova/Mulher_Mercado_Trabalho_Perg_Resp_2012.pdf>. Acesso em 17 set. 2019.

INSTITUTO BRASILEIRO DE GEOGRAFIA E ESTATÍSTICA. Algumas características da inserção das mulheres no mercado de trabalho: Recife, Salvador, Belo Horizonte, Rio de Janeiro, São Paulo e Porto Alegre. 20032008. Rio de Janeiro: IBGE, 2008. Disponível em:

<ftp://ftp.ibge.gov.br/Trabalho_e_Rendimento/Pesquisa_Mensal_de_Empreg o/Estudos/Suplemento_Mulher_2008.pdf >. Acesso em 17 set. 2019.

LAVINAS, Lena; CORDILHA, Ana Carolina; CRUZ, Gabriela Freitas da. Assimetrias de gênero no mercado de trabalho no brasil: rumos da formalização. In: ABREU, Alice Rangel de Paiva; HIRATA, Helena; LOBARDI, Maria Rosa (Org.). Gênero e trabalho no Brasil e na França: perspectivas interseccionais. 1.ed. São Paulo: Boitempo, 2016.p.93-109.

LIMA, Nadege Alves de Souza. A orientação constitucional de igualdade de gênero em casos de licença-maternidade e licença-paternidade. In:

DELGADO, Gabriela Neves; et al. Direito Constitucional do Trabalho: princípios e jurisdição constitucional do TST. São Paulo: LTr, 2018.p. 118129.

MARINHO, Rogério. Projeto de Lei $n^{\circ}$ 6.787, de 2016. comissão especial destinada a proferir parecer ao projeto de lei $n^{0} 6.787$, de 2016 , do poder executivo, que "altera o decreto-lei $\mathrm{n}^{0} 5.452$, de $1^{\circ}$ de maio de 1943 consolidação das leis do trabalho, e a lei $\mathrm{n}^{\circ} 6.019$, de 3 de janeiro de 1974, para dispor sobre eleições de representantes dos trabalhadores no local de 
trabalho e sobre trabalho temporário, e dá outras providências". Brasília: Câmara dos Deputados. Disponível em:

<https://www.camara.leg.br/proposicoesWeb/prop_mostrarintegra?codteor=1 544961>. Acesso em: 11 set. 2019.

MULHERES ganharam 20,5\% menos que os homens em 2018, diz IBGE. 8 mar 2019. Exame. Disponível em:

$<$ https://exame.abril.com.br/economia/mulheres-ganharam-205-menos-queos-homens-em-2018-diz-ibge/>. Acesso em: 17 set. 2019.

MARTINS, Isadora. Reforma Trabalhista ainda é questionada: 14 ADIs tramitam no STF. Postado em 15/09/2019. Atualizado em 16/09/2019. Correio Braziliense. Disponível em:

$<$ https://www.correiobraziliense.com.br/app/noticia/eu-estudante/trabalho-eformacao/2019/09/15/interna-trabalhoeformacao-2019,782563/reformatrabalhista-ainda-gera-polemicas-e-e-questionada-na-justica.shtml>. Acesso em: 11 set. 2019.

OIT. CONVENÇÃO (183). Sobre a proteção à maternidade, de 15.06.2000. [2019] Disponível em: <https://sogi8.sogi.com.br/Arquivo/Modulo113.MRID109/Registro61528/conv en\%C3\%A7\%C3\%A3o\%20oit\%20n\%C2\%BA\%20183,\%20de\%2015-062000.pdf>. Acesso em 20 set. 2019.

ORGANIZAÇÃO DAS NAÇÕES UNIDAS (ONU). Declaração Universal dos Direitos Humanos. Disponível em: <https://nacoesunidas.org/wpcontent/uploads/2018/10/DUDH.pdf>. Acesso em: 11 set. 2019.

PARADELLA, Rodrigo. Diferença cai em sete anos, mas mulheres ainda ganham 20,5\% menos que homens. 08/03/2019. Atualizado em 11/03/2019. Agência IBGE Notícias. Disponível em: 
<https://agenciadenoticias.ibge.gov.br/agencia-noticias/2012-agencia-denoticias/noticias/23924-diferenca-cai-em-sete-anos-mas-mulheres-aindaganham-20-5-menos-que-homens>. Acesso em: 13 set. 2019.

STF invalida norma da Reforma Trabalhista que permitia trabalho de grávidas e lactantes em atividades insalubres. Notícias STF. Brasília, 29 de maio de 2019. Disponível em:

$<$ http://www.stf.jus.br/portal/cms/verNoticiaDetalhe.asp?idConteudo $=41257$ 1>. Acesso em: 12 set. 2019.

TIBURI, Marcia. Feminismo em comum: para todas, todes e todos. 8.ed. Rio de Janeiro: Rosa dos Tempos, 2018.

VIANA, Márcio Túlio; TEODORO, Maria Cecília Máximo. Misturas e fraturas do trabalho: do poder diretivo à concepção do trabalho como necessidade. Disponível em:

<https://pos.direito.ufmg.br/rbep/index.php/rbep/article/download/467/391>. Acesso em 17 set. 2019.

\section{CONGRESSO NACIONAL DOS MAGISTRADOS DA JUSTIÇA DO} TRABALHO - CONAMAT(2018). $2^{a}$ Jornada de Direito Material e

Processual do Trabalho (2017): Reforma trabalhista enunciados aprovados. Belo Horizonte: ANAMATRA, 2018. Disponível em:

<https://www.anamatra.org.br/attachments/article/27175/livreto_RT_Jornad a_19_Conamat_site.pdf> Acesso em: 19 set. 2019.

Recebido em outubro de 2019. Aprovado em dezembro de 2019. 